\title{
A faixa infanto-juvenil como público da ciência e a ciência que lhes é proposta
}

\author{
Carlos Alberto de Carvalho \& Luiza Lages de Souza Ramos \\ Universidade Federal de Minas Gerais \\ E-mail: carloscarvalho0209@gmail.com/ luizalsramosegmail.com
}

\begin{abstract}
Resumo
$\mathrm{O}$ artigo analisa narrativas sobre ciência ber que imagem de ciência as narrativas em três revistas brasileiras, Ciência Hoje, projetam e em que medida visões pedaCiência Hoje das Crianças e Superinte- gogizantes são adotadas como estratégia ressante, com foco na destinação a públi- de aproximação com os públicos refericos infanto-juvenis. Interessa-nos perce- dos.

Palavras-chave: Ciência; Narrativas; Público Infanto-Juvenil; Revista.
\end{abstract}

\section{Resumo}

The article analyzes narratives about sci- interest is to realize what science image ence in three Brazilian journals: Science those narratives produce, and to what exToday, Science Today for Children and tent pedagogical views are adopted as a Superinteressante, focusing on destina- strategy of rapprochement with the afotion to children and youth audiences. Our rementioned audiences.

Palavras-chave: Science; narratives; Public Children and Youth; Magazine.

\section{Imaginário e aprendizado das ciências}

alfabetização científica é uma ideia que nasceu em uma discussão pro-
posta por John Dewey (1934) sobre a necessidade de que os jovens fos-
sem ensinados, durante os anos escolares, a adquirir uma atitude científica.
Para o pesquisador e educador estadunidense, esse movimento ajudaria as 
pessoas a pensar de modo racional e elucidado sobre potenciais problemas que pudessem surgir ao longo de suas vidas.

Durant (2005) explica que, desde então, o termo "designa o que o público em geral deveria saber a respeito da ciência, e a difusão do seu uso reflete uma preocupação acerca dos sistemas educacionais vigentes" (Durant, 2005, p. 13). Para Miller (2005), a comunidade científica, com interesses próprios, tendia a manter a definição de alfabetização científica sob sua autoridade, estipulando uma agenda construída internamente, da ciência para o público.

Durant (2005) descreve três abordagens centrais para a alfabetização científica - todas problemáticas. A primeira, com foco no conteúdo científico, considera que a atividade envolve saber muito sobre ciência: saber o suficiente e saber cada vez mais. Mas, considerando saber muitos fatos ser diferente de ter um bom nível de compreensão da ciência, ele não considera o conhecimento factual a resposta para a alfabetização científica.

Latour (2000) usa o conceito de caixa-preta para trabalhar a dicotomia entre a ciência em construção e a ciência pronta. A caixa-preta seria a marca da exatidão, da ciência pronta. Ela engendra a substituição de questões muito complexas, anteriormente investigadas, por um elemento fixo, dado como certo e pelo qual os pesquisadores passam sem abrir. As caixas se mantêm fechadas para que a atividade científica não se torne impossível. Mas as marcas da ciência pronta são obras da ciência em construção. "Incerteza, trabalho, decisões, concorrência, controvérsias, é isso que vemos quando fazemos um flashback das caixas-pretas certinhas, frias, indubitáveis para o seu passado recente" (Latour, 2000, p. 16).

Para Latour (2000), falar sobre ciência significa abrir as caixas-pretas, falar sobre a ciência em construção. Falar da ciência pronta seria não só reducionista, como possivelmente mostrar às pessoas o que elas já conhecem. Incluindo ao escopo uma dimensão pedagogizante, a não abertura das caixas-pretas implicaria na não inclusão da dimensão incerta, mutável e transformadora da ciência - que nunca se mostrou pronta e intocável na história da humanidade. Seria ignorar a história e as qualidades inerentes à ciência, processos pelos quais um futuro cientista teria que percorrer.

A partir da perspectiva da construção da ciência, entramos na segunda e terceira abordagens possíveis à alfabetização científica. A segunda sendo saber como a ciência funciona. Com ênfase nos processos, os alunos deveriam aprender ciência a praticando. Durant (2005) toma emprestada a avaliação 
A faixa infanto-juvenil como público da ciência e a ciência que lhes é proposta

de outro pesquisador conterrâneo, Jon Miller, para aquela que seria uma pessoa cientificamente alfabetizada: a) possuir um vocabulário básico de termos e conceitos científicos; b) compreender os processos ou métodos científicos para colocar em teste nossos modelos de realidade; c) compreender o impacto da ciência e da tecnologia sobre a sociedade. O que o autor aponta é que, até para os cientistas, há muita dificuldade em entender de fato esses processos, que, como os fatos, são impuros e heterogêneos.

A terceira e última abordagem recai sobre saber como a ciência realmente funciona (com suas impurezas e constantes transformações). O processo social da produção do conhecimento científico envolve um conjunto de conhecimentos existentes; um cientista que identifica um problema ou uma possibilidade de contribuição para o corpus; a condução de um trabalho; a descrição do trabalho; o julgamento do trabalho; e a entrada do trabalho no corpus de conhecimento existente (Durant, 2005). Para o autor, a falha mais séria do ponto de vista usual é justamente projetar as qualidades do conhecimento científico sobre os cientistas, quando este deveria ser um trabalho objetivo, aberto e produzido a partir de métodos estipulados em comunidade. Mas ele entende que, apesar de a ciência ser mais que um cientista (ser um contexto), o cientista e a narrativa do cientista são mais interessantes e acabam, consequentemente, por ganhar destaque nas narrativas da ciência.

A partir de narrativas sobre astronomia nas revistas Ciência Hoje, Ciência Hoje das Crianças e Superinteressante, avaliamos na sequência como o caráter educativo para públicos infanto-juvenis aparece nas três publicações.

\section{Tessitura histórica e conceitual da astronomia}

Quando traçamos a história da astronomia, ponto crucial e norteador das questões relevantes acerca das motivações e observações primeiras do céu, a investigação do nosso lugar na disposição do universo aponta, primordialmente, para os estudos do Sistema Solar. Na edição de abril de 2009, a Ciência Hoje aborda tais questões no texto "O Sistema Solar e seus corpos extraordinários" e deixa claro tal entendimento a respeito do nosso sistema planetário para a história da astronomia.

Mercúrio, Vênus, Marte, Júpiter e Saturno foram os primeiros corpos denominados planetas. A Terra só entrou na lista no início do século 17, com a aceitação do heliocentrismo, e Urano e Netuno foram descobertos anos de- 
pois, a partir de novos instrumentos de observação e teorias (Lazzaro, 2009, Ciência Hoje). Com tal explicação, a narrativa constrói a perspectiva histórica da astronomia, associada à noção de avanço científico e tecnológico. Mas o foco do artigo se insere na história recente, relacionada à descoberta de Plutão, em 1930, seguida dos objetos transnetunianos, em 1992, e toda a discussão subsequente a respeito das categorizações de corpos celestiais.

Esse pode ser considerado o melhor exemplo da dificuldade em separar de forma inequívoca as populações no Sistema Solar. Plutão foi descoberto após anos de procura pelo 'planeta X', que deveria ser responsável pelas discrepâncias que continuavam a existir na posição prevista de Urano, mesmo após a descoberta de Netuno (em tempo: hoje, sabemos que essas discrepâncias vinham da massa incorreta adotada para Urano). (Lazzaro, 2009, Ciência Hoje, p. 42)

A expectativa e busca pelo planeta se insere dentro da perspectiva constituinte de uma teoria segundo observado por Hawking (2006), um modelo capaz de fazer previsões; e dentro da noção de ciência moderna (Santos, 1989), sendo a empiria subsequente às previsões matemáticas e teorias produzidas. É interessante notar como a não concordância de Plutão com as previsões dos astrônomos à época de sua descoberta apontava então para falhas em tal modelo - que seriam compreendidas anos depois, como explica a autora e, ainda assim, este foi classificado como planeta até 2006, além de alegada razão às perturbações na órbita de Urano. Ao chamar a atenção para todas essas questões e não questionar tal compreensão anterior do corpo celeste, a narrativa da Ciência Hoje atenta para a mutabilidade da ciência, como algo inerente e natural ao processo:

Mesmo assim, era o único corpo descoberto naquela região do Sistema Solar, daí sua inquestionável classificação como planeta naquele momento. E, como a ciência evolui juntamente com o desenvolvimento tecnológico, também pode mudar a forma de classificar os objetos em classes que representem da melhor forma as características comuns a eles. (Lazzaro, 2009, Ciência Hoje, p. 42)

A astronomia é narrada, assim, como uma ciência sendo construída e construída coletivamente. O que caracterizaria uma determinada categoria de objetos é definido em conjunto pelos astrônomos, organizados na União 
A faixa infanto-juvenil como público da ciência e a ciência que lhes é proposta

Astronômica Internacional. O texto apresenta as recentes reuniões que deram origem à determinação das três classes de objetos no Sistema Solar (planetas, planetas anões e pequenos corpos), incutindo certa unidade aos estudos desses corpos, além de chamar a atenção para o aspecto humano - as escolhas e o olhar dos profissionais, em rede - na metodologia convocada às pesquisas.

Historicamente, essa perspectiva coletiva e transitória das teorias astronômicas se mostra bem resolvida nas três revistas. É comum às construções textuais - pelo menos dos textos de cunho didático - o desenho histórico dos sujeitos narrativos, a contextualização do lugar que ocupam dentro de subconjuntos das narrativas da astronomia e que se inserem, em outra instância, no amplo conjunto da ciência, de forma geral.

$\mathrm{Na} \mathrm{CH}$ das Crianças narra-se que "Houve uma época em que se pensava que o Sol girava ao redor da Terra" (Trevisan, 2009, p. 7); na Superinteressante, que "Os astrônomos, para onde quer que olhassem, só viam matéria. A antimatéria havia sido quase totalmente jogada para escanteio" (Nogueira, 2009, p. 80), e hoje a antimatéria ocupa posição de destaque em grandes e caras pesquisas ao redor do mundo; na Ciência Hoje, que "Forjada a partir da analogia com fenômenos magnéticos observados da Terra, a física celeste kepleriana reflete a dissolução da fronteira que na Antiguidade e na Idade Média separava a Terra e o céu como regiões essencialmente distintas" (Itokazu, 2009, p. 74).

O último exemplo é parte do texto "O nascimento de uma nova física celeste", voltado à memória do astrônomo Johannes Kepler, e compreende bom lugar de reflexão ao que aqui buscamos representar, sobre as narrativas históricas presentes nos textos. Kepler é apresentado como personagem revolucionário, inserido em um contexto científico que se dividia em três sistemas de mundo rivais, nenhum realmente apoiado pelo astrônomo, e nenhum realmente passível de comprovação observacional - ao menos não em sua totalidade.

Partindo da crítica ao modelo ptolomaico e da adoção de princípios e observações produzidos por Copérnico e Tycho Brahe, Kepler buscava encontrar e entender as posições e o movimento dos astros no céu, de tal forma que teria sido pioneiro na incursão da física aos estudos astronômicos.

A força solar, introduzida como explicação causal para o movimento dos planetas, é algo revolucionário à época de Kepler. Isso fica patente 
na crítica que lhe foi feita por seu professor de astronomia na Universidade de Tübingen, Michel Maestlin (1550-1631), para quem "questões astronômicas deveriam ser tratadas astronomicamente, por meio de hipóteses astronômicas, e não por causas e hipóteses físicas". (Itokazu, 2009, Ciência Hoje, p. 73)

O professor de Kepler é convocado à narrativa como representante de uma corrente teórica, apesar de vigente, contrária às ideias do astrônomo, obstáculo vivenciado e superado por este no correr da história - creditando a Kepler um caráter heroico. Superada se torna também essa ideia de astronomia, a da perfeição, dissociada da física e da Terra. "Kepler transforma o sistema de Copérnico em um heliocentrismo físico. O Sol ocupa posição central no céu e, além de iluminar o mundo, é responsável pelo movimento dos planetas" (Itokazu, 2009, p. 74). E, eventualmente, Kepler também seria ultrapassado, com sua física "fadada a ser substituída pela mecânica celeste de Isaac Newton" (p. 75).

No artigo "O ruído do Universo" conta-se a história da radiação cósmica de fundo em micro-ondas (RCFM) na evolução do universo e dentro dos estudos astrofísicos. Descrita como uma das mais poderosas ferramentas de pesquisa da cosmologia, o ruído faz parte da história recente das observações astronômicas, desde a sua descoberta acidental, em 1931, com a detecção de ondas de rádio provenientes do espaço pelo engenheiro Karl Jansky. A partir desse ponto, diversos cientistas e instituições tomam postos de personagens com participações cronologicamente dispostas na narrativa, dentro de um tradicional modelo de contar histórias.

A abertura do texto, para contextualizar a RCFM, se dá com a clássica estrutura de "era uma vez...": "De seu início, supostamente em um estado de grande densidade e alta temperatura, o universo evoluiu constantemente, se expandindo" (Villela Neto, 2009, p. 29). Insere então uma explicação atual do que se considera ser a radiação. Depois, e pela maior parte da narrativa, traça uma linha temporal com os eventos científicos que a envolveram - cada nova descoberta, as dificuldades com a empiria, problemas tecnológicos, teóricos e de aceitação na comunidade científica:

Uma grande preocupação tomou conta da comunidade científica. Tentativas de se medir o espectro da RCFM foram feitas para verificar se ele realmente era consistente com o previsto pela lei que rege o compor- 
A faixa infanto-juvenil como público da ciência e a ciência que lhes é proposta

tamento de um corpo negro (...) no entanto, não definiram claramente a situação. (Villela Neto, 2009, p. 31)

Por fim, o texto não apresenta caráter conclusivo, indicando as aberturas, novos problemas, "desafios" e perspectivas no estudo da radiação. Apesar de elementos que apontam para uma perspectiva da ciência fechada (como o subtítulo "Prova definitiva", onde se dispõem observações empíricas da RCFM como de origem cosmológica), de modo geral, a narrativa envolve a abertura de uma caixa-preta. Obviamente da perspectiva de um leigo, já que não passa por aspectos realmente técnicos, mas apresenta a evolução da temática, com os percalços produtivos, as dúvidas e a estrutura em rede da comunidade científica. Nota-se que na Ciência Hoje a maioria dos textos segue esse padrão, com narrativas que ganham mais espaço (número de páginas) para serem desenvolvidas e consequentemente tornam-se mais aprofundadas, revelando mais aspectos da construção da astronomia.

$\mathrm{Na}$ revista Superinteressante o caráter dúbio ciência pronta/ciência em construção se acentua, particularmente entre as temáticas brevemente discutidas nas notas, que ocupam entre meia e uma página da revista. Apesar de pontos teóricos e observacionais historicamente estáveis - portanto mais consolidados - serem pouco ou nada discutidos, reconhecemos o esforço narrativo em apresentar múltiplas visões e as incertezas relativas aos temas abordados, mesmo com a pouca profundidade dos textos, através das polêmicas existentes no meio científico. Essa característica fica mais evidente nas narrativas referentes a novas descobertas e atualidades. A revista dá muito espaço às novidades no meio científico, mas o presente parece ser também associado à ideia de construção e, portanto, ainda estar à prova.

Entrando na faixa etária infantil, a $\mathrm{CH}$ das Crianças tende, na balança entre construção e conclusão, a uma ideia de ciência pronta. Pensamos que tal perspectiva se ligue a dois elementos: o primeiro associado à linha editorial da publicação, cujos textos buscam tratar de temáticas não atuais, frias, e consequentemente mais estáveis entre os pares científicos; segundo, à maior dimensão pedagogizante da revista, que pode caracterizar narrativas menos contestadoras da ciência, mais assertivas sobre o seu lugar e consequência da noção de que ensinamos aquilo que sabemos.

Inclusive, termos como "sabemos", "conhecemos" e "vemos", além de falas direcionadas ao leitor ("Você sabia que..."; "já pensou que...") são recor- 
rentes nos textos ao tratar da astronomia: "Já sabemos que o movimento ao redor do Sol leva um ano para se completar. Sabemos, também, que enquanto gira em torno do astro-rei, a Terra vai dando voltas em torno do seu próprio eixo" (Trevisan, 2009, CH das Crianças, p. 8); "Você, certamente, já reparou que a Lua muda de aspecto no céu" (Guedes, 2009, p. 18); "Você já pensou que a cada aniversário a Terra completa uma viagem ao redor do Sol?" (2009, CH das Crianças, p.19); "Talvez você não saiba, mas os telescópios concentram a luz coletada por seus grandes espelhos (...)" (Castilho, 2009, CH das Crianças, p. 12).

Nesse espaço de explicação do mundo, as caixas-pretas são dadas e raramente abertas. Na resposta à pergunta "Por que o Sol vai morrer", na edição de julho de 2009 da revista, a astronomia é fechada e conclusiva. A narração estipula que o Sol é uma estrela, como qualquer outra, originada de poeira estelar e fadada ao fim. A história do Sol é assim contada cronologicamente: como se deu seu nascimento, sua evolução e qual será seu futuro. É uma narrativa tradicional, com início, meio e fim, sem espaços vazios ou disposição de dúvidas. A única questão deixada em aberto se refere ao que a morte do Sol significaria para a humanidade, algo ainda imprevisível: "Será o fim? Quem sabe? (...) é de se esperar que, com sua sabedoria, (a humanidade) seja capaz de descobrir e viajar para outros mundos e preservar nossa civilização" (Prado, 2009, p. 17).

Apesar de lidar com fatos fechados, parece ser interessante à $\mathrm{CH}$ das $\mathrm{Cri}$ anças uma interação mais aberta do leitor com a narrativa, a partir de um engajamento imaginativo lúdico que coloca a criança na posição de refletir e produzir as próprias conclusões a partir de observações próprias. É uma forma de inserir narrativamente a metodologia, o processo de construção da astronomia. E, assim, revela-se aquilo que é importante para o estudo dos astros, como a observação, os mecanismos, os instrumentos e a matemática.

\section{Referências bibliográficas}

Castelfranchi, Y. et al. (2008). O cientista é um bruxo? Talvez não: ciência e cientistas no olhar das crianças. In L. Massarani (org.) Ciência e criança: a divulgação científica para o público infanto-juvenil, (pp. 14-19). Rio de Janeiro: Museu da Vida / Casa Oswaldo Cruz / Fiocruz. 
A faixa infanto-juvenil como público da ciência e a ciência que lhes é proposta

Durant, J. (2005). O que é alfabetização científica?. In L. Massarani, et al (org.) Terra incógnita: a interface entre ciência e público. Rio de Janeiro: Vieira \& Lent, Casa da Ciência: FIOCRUZ.

Hawking, S. (2005). Os gênios da ciência: sobre o ombro de gigantes. Tradução de Marco Moriconi. Rio de Janeiro: Elsevier.

Latour, B. (2000). Ciência em ação: como seguir cientistas e engenheiros sociedade afora. $2^{\mathrm{a}}$.ed. São Paulo: Editora UNESP.

Miller, S. (2005). Os cientistas e a compreensão pública da ciência. In L. Massarani, et al (org.) Terra incógnita: a interface entre ciência e público. Rio de Janeiro: Vieira \& Lent: UFRJ, Casa da Ciência: FIOCRUZ.

Santos, B. (1989). Introdução a uma ciência pós-moderna. Rio de Janeiro: Graal.

\section{Referências das revistas}

Castilho, B. (2009). Você sabia que o Brasil tem telescópios de última geração fora do próprio território?. Ciência Hoje das Crianças, julho, 203: 12. Rio de Janeiro.

Guedes, L. (2009). Pintando a Lua. Ciência Hoje das Crianças, julho, 203: 18. Rio de Janeiro.

Itokazu, A. (2009). O nascimento de uma nova física celeste. Ciência Hoje, abril, 258: 73-75. Rio de Janeiro.

Lazzaro, D. (2009). O sistema Solar e seus corpos extraordinários. Ciência Hoje, abril, 258: 40-45. Rio de Janeiro.

Nogueira, J.S. (2009). Antimatéria. Superinteressante, janeiro, 261: 78-81. São Paulo.

Nogueira, J.S. (2009) Por dentro do Sistema Solar. Ciência Hoje das Crianças, julho, 203: 26-27. Rio de Janeiro.

Prado, L. (2009). Por que o Sol vai morrer?. Ciência Hoje das Crianças, julho, 203: 17. Rio de Janeiro.

Russomano, T. \& Beuermann, B. (2009). Como se tornar um astronauta. Ciência Hoje das Crianças, julho, 203: 10-11. Rio de Janeiro.

Santos, M.R. (2009). A bactéria que veio do céu. Superinteressante, julho, 267: 41. São Paulo. 
Trevisan, R. (2009). Astronomia no dia-a-dia. Ciência Hoje das Crianças, julho, 203: 6-9. Rio de Janeiro.

Trevisan, R. (2009). Vida na Terra pode ter vindo do espaço. Superinteressante, outubro, 270: 22. São Paulo.

Villela Neto, T. (2009). O ruído do universo. Ciência Hoje, dezembro, 266: 28-33. Rio de Janeiro. 